\title{
$\alpha$-bisabolol-loaded lipid-core nanocapsules reduce lipopolysaccharide-induced pulmonary inflammation in mice
}

This article was published in the following Dove Press journal:

International Journal of Nanomedicine

19 June 2017

Number of times this article has been viewed

\author{
Ana Paula L D'Almeida ${ }^{1, *}$ \\ Maria T Pacheco de \\ Oliveiral,* \\ Éverton T de Souza' \\ Diego de Sá Coutinho' \\ Bianca T Ciambarella' \\ Cristiano R Gomes' \\ Thatiana Terroso ${ }^{2}$ \\ Sílvia S Guterres ${ }^{2}$ \\ Adriana R Pohlmann ${ }^{3}$ \\ Patrícia MR Silva' \\ Marco A Martins' \\ Andressa Bernardi' \\ 'Laboratory of Inflammation, \\ Oswaldo Cruz Institute, Oswaldo \\ Cruz Foundation, Rio de Janeiro, \\ Brazil; ${ }^{2}$ Pharmaceutical Sciences \\ Post-Graduation Program, College of \\ Pharmacy, Federal University of Rio \\ Grande do Sul, Porto Alegre, Brazil; \\ ${ }^{3}$ Department of Organic Chemistry, \\ Institute of Chemistry, Federal \\ University of Rio Grande do Sul, \\ Porto Alegre, Brazil \\ *These authors contributed equally \\ to this work
}

\begin{abstract}
Acute respiratory distress syndrome (ARDS) is a severe clinical condition of respiratory failure due to an intense inflammatory response with different etiologies. Despite all efforts, therapy remains limited, and ARDS is still associated with high mortality and morbidity. Plants can provide a vast source of active natural products for the discovery of new drugs. $\alpha$-bisabolol ( $\alpha$-bis), a constituent of the essential oil from chamomile, has elicited pharmacological interest. However, the molecule has some limitations to its biological application. This study was conducted to develop a drug delivery system using lipid-core nanocapsules (LNCs) to improve the anti-inflammatory effects of orally administered $\alpha$-bis. $\alpha$-bis-loaded LNCs ( $\alpha$-bis-LNCs) were prepared by interfacial deposition of poly( $\varepsilon$-caprolactone) and orally administered in a mouse model of ARDS triggered by an intranasal administration of lipopolysaccharide (LPS). We found that $\alpha$-bis-LNCs (30, 50, and $100 \mathrm{mg} \mathrm{kg}^{-1}$ ) significantly reduced airway hyperreactivity (AHR), neutrophil infiltration, myeloperoxidase activity, chemokine levels (KC and MIP-2), and tissue lung injury 18 hours after the LPS challenge. By contrast, free $\alpha$-bis failed to modify AHR and neutrophil accumulation in the bronchoalveolar lavage effluent and lung parenchyma and inhibited elevation in the myeloperoxidase and MIP-2 levels only at the highest dose. Furthermore, only $\alpha$-bis-LNCs reduced LPS-induced changes in mitogen-activated protein kinase signaling, as observed by a significant reduction in phosphorylation levels of ERK1/2, JNK, and p38 proteins. Taken together, our results clearly show that by using LNCs, $\alpha$-bis was able to decrease LPS-induced inflammation. These findings may be explained by the robust increase of $\alpha$-bis concentration in the lung tissue that was achieved by the LNCs. Altogether, these results indicate that $\alpha$-bis-LNCs should further be investigated as a potential alternative for the treatment of ARDS.
\end{abstract}

Keywords: acute respiratory distress syndrome, nanotechnology, drug delivery, pulmonary inflammation, $\alpha$-bisabolol, anti-inflammatory effects

\section{Introduction}

Acute respiratory distress syndrome (ARDS) is a severe inflammatory lung condition that is characterized by the damage of the alveolar capillary barrier, leading to extravasation of exudate into the airspace, decreased lung compliance, and hypoxemia. ${ }^{1,2}$ Despite considerable recent advances in the understanding of the mechanism underlying ARDS pathogenesis, supportive therapies remain the mainstay of treatment of this disease. ${ }^{3,4}$ Because of the high mortality rate and its substantial impact on public health, novel therapeutic approaches for ARDS are badly needed. ${ }^{5}$

Originally based in popular use by successive generations, traditional medicine has been a source of pharmacotherapy for millions of people worldwide. ${ }^{6-8}$ Plants
Correspondence: Andressa Bernardi Fundação Oswaldo Cruz, Avenida Brasil 4365, Manguinhos, Rio de Janeiro, 21040-360, Brazil

Email andressa.bernardi@ioc.fiocruz.br 
can provide a vast source of active natural products for the discovery of new drugs. Secondary metabolites from plants, such as terpenes, phenols, and alkaloids, are known to modulate the expression of proinflammatory signals and have shown potent biological activities, providing lead compounds in drug discovery for the treatment of many conditions and diseases, for instance, microbial infections, cancer, and inflammation. ${ }^{9,10}$

$\alpha$-bisabolol ( $\alpha$-bis) is a small, plant-derived, oily sesquiterpene alcohol found as the major constituent of the essential oil from German chamomile (Chamomilla recutita (L.) Rauschert), a plant used for centuries for its medicinal properties. ${ }^{11,12} \alpha$-bis has shown anti-inflammatory, ${ }^{13}$ antimicrobial, antifungal, larvicidal, ${ }^{14}$ leishmanicidal, ${ }^{15}$ and antitumor properties. ${ }^{16,17}$ Despite these protective effects, the therapeutic potential of $\alpha$-bis in inflammatory lung diseases has not yet been investigated. One limitation is that $\alpha$-bis is a highly lipophilic and easily oxidizable compound, easily forming two bisabolol oxides. ${ }^{18}$ Thus, the incorporation of $\alpha$-bis into nanoparticles would be an alternative to minimize oxidation of the molecule and improve its delivery into the focus of the lesion. In this way, we hypothesize that when incorporated into a lipid-core nanocapsule (LNC) system, $\alpha$-bis may exhibit an improvement in anti-inflammatory properties.

Nanotechnology may be considered the science with the potential to produce materials and/or strategies that involve manipulation of matter at the nanometer scale. ${ }^{19}$ For pharmaceutical applications, molecules are arranged into relatively inert, biodegradable, and nontoxic carriers, which is a promising approach to improving their delivery. ${ }^{20}$ Nanocapsules are vesicular systems in which the drug/active principle can be confined in an oily cavity surrounded by a polymeric wall ${ }^{21}$ that allows the therapeutic effectiveness to be increased. Thus, nanoencapsulation of drug substances has demonstrated improved stability, ${ }^{22}$ controlled release, ${ }^{21-23}$ improved activity, ${ }^{24}$ targeted to a specific organ or tissue, ${ }^{25}$ and reduced side effects. ${ }^{26}$

Considering the well-established anti-inflammatory properties of $\alpha$-bis as well as the possibility of improving its delivery and translational prospective, the aim of this study was to evaluate the effectiveness of $\alpha$-bis-loaded lipid-core nanocapsules ( $\alpha$-bis-LNCs) in a mouse model of acute lung injury (ALI) induced by lipopolysaccharide (LPS).

\section{Materials and methods Preparation of LNCs}

LNCs formulations were prepared by interfacial deposition of polymer. At $40^{\circ} \mathrm{C}$, poly $(\varepsilon$-caprolactone) $(250 \mathrm{mg})$, sorbitan monostearate (95 mg), $\alpha$-bis (250 mg), and capric/ caprylic triglyceride $(150 \mathrm{mg})$ were dissolved in acetone $(60 \mathrm{~mL})$ and ethanol $(7.5 \mathrm{~mL})$. In a separate flask, polysorbate $80(192.5 \mathrm{mg})$ was added to $133 \mathrm{~mL}$ of water. The organic solution was injected into the aqueous phase under magnetic stirring at room temperature. After 10 minutes, acetone and ethanol were eliminated, and the formulation was concentrated under reduced pressure. The final volume was adjusted in a volumetric flask to $25 \mathrm{~mL}$. Drug-unloaded nanocapsules (ULNCs) were prepared as described above, omitting the $\alpha$-bis content and adding the inert oil (capric/ caprylic triglyceride) as a single oil. This formulation was used as a control vehicle.

\section{Characterization of LNCs}

After preparation, $\alpha$-bis-LNCs and ULNCs were characterized by using potentiometry, dynamic light scattering, laser Doppler microelectrophoresis, and liquid chromatography. All these measurements were taken in (at least) triplicate batches. The $\mathrm{pH}$ was determined in a calibrated potentiometer (B474; Micronal, São Paulo, Brazil). The particle size distribution, hydrodynamic mean diameter, polydispersity index (PDI), and zeta potential were determined by a Zetasizer ${ }^{\circledR}$ Nano-ZS ZEN 3600 model (Malvern Instruments, Malvern, UK). For particle sizing, the formulations were diluted with prefiltered water (MilliQ ${ }^{\circledR}$ ), while for zeta potential measurements, they were diluted with $10 \mathrm{mmol} \mathrm{L}^{-1} \mathrm{NaCl}$ aqueous solution. The total concentration (drug content) of $\alpha$-bis in the $\alpha$-bis-LNCs formulation was measured by reverse-phase high-performance liquid chromatography (HPLC; PerkinElmer S-200, with an S-200 injector, an ultraviolet-visible [UV-Vis] detector, a guard column; PerkinElmer, Waltham, MA, USA), and a Nova-Pak C18 column (150 mm, $4.9 \mathrm{~mm}$, $4 \mu \mathrm{m}$; Waters, Quebec, Canada). The mobile phase consisted of acetonitrile/water (60:40, volume to volume ratio $[\mathrm{v} / \mathrm{v}])$ adjusted to an apparent $\mathrm{pH}$ of $4.5 \pm 0.5$ with $10 \%(\mathrm{v} / \mathrm{v})$ acetic acid. Each formulation $(100 \mu \mathrm{L})$ was treated with acetonitrile $(10 \mathrm{~mL})$ to extract the drug. The solution was filtered (Millipore, $0.45 \mu \mathrm{m}$; Merck Millipore, Billerica, MA, USA) and injected $(20 \mu \mathrm{L}) . \alpha$-bis was detected at $207 \mathrm{~nm}$ with a retention time of 11 minutes. Linear calibration curves for $\alpha$-bis were obtained in the range of 2.00-25.00 $\mu \mathrm{g} \mathrm{mL}^{-1}$, presenting correlation coefficients $>0.99$. The encapsulation efficiency was determined by an ultrafiltration-centrifugation technique (Ultrafree ${ }^{\circledR}-\mathrm{MC}, 10,000 \mathrm{MW}$; Merck Millipore) at $15,300 \times g$ for 10 minutes. The amount of $\alpha$-bis encapsulated in the nanocapsules was calculated from the difference between the total and free drug concentrations determined 
in the nanocapsule suspension and in the ultrafiltrate, respectively.

\section{Animals}

Male A/J mice (18-20 g) were obtained from the Oswaldo Cruz Foundation (FIOCRUZ, Rio de Janeiro, Brazil). They were kept in the animal-housing facilities with 5 animals per cage under controlled temperature $\left(22^{\circ} \mathrm{C}-25^{\circ} \mathrm{C}\right)$, with a 12-hour light-dark cycle ( 6 am- $6 \mathrm{pm})$ and food and water ad libitum. This study and the procedures were performed in accordance with the guidelines of the Guide for the Care and Use of Laboratory Animals and the recommendations of the Animal Ethics Committee of the Oswaldo Cruz Foundation (Protocol LW23/10; Comissão de Ética no Uso de AnimaisFIOCRUZ), which also approved this research.

\section{Treatment protocol}

Treatments with free $\alpha$-bis or $\alpha$-bis-LNCs were administered orally (gavage) at doses of 30,50 , or $100 \mathrm{mg} \mathrm{kg}^{-1} 4$ hours before the challenge with LPS. For vehicle control, the animals were treated with ULNCs at the same amount of the highest dose $\left(100 \mathrm{mg} \mathrm{kg}^{-1}\right)$. For administration of free $\alpha$-bis, an oil dispersion in saline was prepared to form an emulsion with the same concentration of $\alpha$-bis present in the nanocapsule formulation. The analyses were performed 18 hours after the LPS challenge.

\section{Murine model of LPS-induced lung acute inflammation}

The murine model of acute lung inflammation induced by LPS was established with local adaptations as previously reported. ${ }^{27}$ Briefly, the mice were anesthetized with isoflurane aerosol with a constant flow of $\mathrm{O}_{2}\left(3.5 \mathrm{kgf} \mathrm{cm}^{-2}\right.$; BRASMED, Guarulhos, Brazil) and then underwent an intranasal challenge with LPS $(25 \mu \mathrm{g} / 25 \mu \mathrm{L})$. In the control group (saline group), LPS was replaced by sterile $0.9 \% \mathrm{NaCl}$.

\section{Invasive assessment of respiratory mechanics}

Airway reactivity was assessed as a change in airway function after challenge with aerosolized methacholine in a FinePoint R/C Buxco Platform (Buxco Electronics, Sharon, CT, USA). Mice were anaesthetized with sodium pentobarbital (60 $\mathrm{mg} \mathrm{kg}^{-1}$ intraperitoneal [IP]; Cristália, Itapira, Brazil). Neuromuscular activity was blocked with bromide pancuronium (1 $\mathrm{mg} \mathrm{kg}^{-1}$ ). Tracheostomized mice were mechanically ventilated (MiniVent, Buxco Electronics, Wilmington, NC, USA) only with atmospheric air (fraction of inspired $\mathrm{O}_{2}, \sim 20 \%$ ), and lung function was assessed. Anesthetized animals were maintained at $36.0^{\circ} \mathrm{C}-36.5^{\circ} \mathrm{C}$ using a heating pad and subjected to baseline mechanical ventilation conditions (tidal volume $=0.25 \mathrm{~mL}$, positive end-expiratory pressure $=0.160 \mathrm{cmH}_{2} \mathrm{O}$, and respiratory frequency $=100$ breaths $\mathrm{min}^{-1}$ ) throughout the assessment of the respiratory mechanics ( $\sim 30$ minutes). Airflow and transpulmonary pressure were recorded by using a Buxco Pulmonary Mechanics Processing System (Buxco Electronics). This system was used to calculate lung elastance $\left(\mathrm{mL} \mathrm{cmH} \mathrm{O}^{-1}\right)$ in each breath cycle. Analog signals from the computer were digitized by using a Buxco analog/digital converter (Buxco Electronics). The mice were allowed to stabilize for 5 minutes, and increasing concentrations of methacholine $\left(3,9\right.$, and $\left.27 \mathrm{mg} \mathrm{mL}^{-1}\right)$ were aerosolized for 5 minutes each to assess airway responsiveness. Baseline pulmonary parameters were assessed following aerosol of PBS. The results comprised the mean absolute values of the responses of lung elastance collected during the 5 minutes after the administration of methacholine aerosol.

\section{Cell recovery from the airway lumen}

After the evaluation of airway hyperreactivity (AHR), the mice were killed by anesthetic overdose (sodium pentobarbital, $500 \mathrm{mg} \mathrm{kg}^{-1}$, IP), and bronchoalveolar lavage (BAL) was performed as previously reported. ${ }^{28}$ Briefly, the lavage fluid was centrifuged, and cell pellets were resuspended in $250 \mu \mathrm{L}$ of PBS containing $10 \mathrm{mM}$ EDTA for enumeration of total leukocytes by means of a Neubauer chamber. Cytospin slides were prepared from BAL fluid (BALF) and stained with MayGrunwald-Giemsa stain. At least 100 cells were counted per slide by using light microscopy, and they were differentiated according to the standard morphological criteria.

\section{Chemokine quantification}

After lung perfusion with saline and EDTA (20 mM), the lung was removed, immediately frozen in liquid nitrogen, and stored at $-80^{\circ} \mathrm{C}$. Tissue samples were homogenized on ice using a $\mu \mathrm{H}$ homogenizer (Omni International, Kennesaw, GA, USA) for 30 seconds in $1 \mathrm{~mL}$ of PBS containing $0.05 \%$ Triton X-100 and a protease inhibitor cocktail (Complete ${ }^{\circledR}$; Hoffmann-La Roche Ltd., Basel, Switzerland). The resulting supernatants were isolated after centrifugation at $10,000 \times g$ for 15 minutes at $4^{\circ} \mathrm{C}$. Murine MIP-2 (CXCL-2), and KC chemokine levels were measured in samples by using enzyme-linked immunosorbent assay according to the instructions provided by the manufacturer (DuoSet ${ }^{\circledR} ;$ R\&D Systems, Minneapolis, MN, USA). The cytokine levels 
were normalized to total protein levels measured by using a bicinchoninic acid (BCA) assay ${ }^{29}$ and expressed as picograms of cytokine per milligram of protein.

\section{Myeloperoxidase (MPO) activity assay}

MPO activity was assessed as previously described with minor modifications. ${ }^{30}$ Briefly, 18 hours after the LPS challenge, the mice were killed, and the right lungs (perfused) were excised, homogenized in $1 \mathrm{~mL}$ of Hank's solution, and centrifuged at $1,950 \times g$ for 10 minutes at $4^{\circ} \mathrm{C}$. The pellet was suspended in $0.5 \mathrm{~mL}$ of $0.2 \% \mathrm{NaCl}$ followed by $0.5 \mathrm{~mL}$ of hypertonic solution of $1.6 \% \mathrm{NaCl}$ and centrifuged at $2,000 \times g$ for 10 minutes at $4^{\circ} \mathrm{C}$. Next, the pellet was suspended in $1 \mathrm{~mL}$ of hexadecyltrimethylammonium bromide (HTAB) and recentrifuged at $1,700 \times g$ for 15 minutes at $4^{\circ} \mathrm{C}$. The supernatant was collected and centrifuged at $15,300 \times g$ for 15 minutes at $4^{\circ} \mathrm{C}$. It was added to a 96 -well plate with $50 \mu \mathrm{L}$ of sample, $50 \mu \mathrm{L}$ of HTAB, and $50 \mu \mathrm{L}$ of orthodianisidine $\left(0.68 \mathrm{mg} \mathrm{mL}^{-1}\right)$. The plate was maintained at $37^{\circ} \mathrm{C}$ for 15 minutes, and then, $50 \mu \mathrm{L}$ of $\mathrm{H}_{2} \mathrm{O}_{2}(0.006 \%)$ was added to each well. After 10 minutes, $50 \mu \mathrm{L}$ of sodium azide (1\%) was added. The analysis was performed by measuring the absorbance at a wavelength of $460 \mathrm{~nm}$ using a SpectraMax M5 plate reader (Molecular Devices LLC, Sunnyvale, CA, USA), and the result is expressed as $\mathrm{U}$ (enzyme unit) per mg of protein.

\section{Histological analysis of lung}

The perfused lung was removed, and the left lobe was taken for histological analysis and immediately fixed in Millonig's buffer solution ( $\mathrm{pH}=7.4$ ) with 4\% paraformaldehyde to preserve tissue architecture. Routine histological techniques were used to paraffin-embed samples, and 4- $\mu \mathrm{m}$ thick sections were stained with H\&E. The lung tissues stained with H\&E were scanned and analyzed by using the Pannoramic Viewer program (3DHISTECH Ltd., Budapest, Hungary). This staining was used to analyze lung damage and is presented by a "score." The score represents the evaluation of a set of criteria, such as infiltration of inflammatory cells in the airspace or vessels, alveolar congestion, and thickness of the alveolar wall, and evaluates lung damage via a numerical rating system that ranges from 0 to 4 (score), with no damage $=0$, minor damage $=1$, moderate damage $=2$, severe damage $=3$, and very severe damage $=4 .{ }^{31}$ This analysis was performed by evaluating the entire lung section at a magnification of $\times 10$.

\section{Western blot analysis}

Lung tissue was homogenized in radioimmunoprecipitation assay buffer with a protease and phosphatase inhibitor cocktail (1:100; Thermo Scientific, Swedesboro, NJ, USA). The homogenates were denatured for 5 minutes at $100^{\circ} \mathrm{C}$ and then centrifuged at $10,000 \times g$ for 10 minutes. The supernatant was collected, and the total protein was quantified by using BCA method; $\beta$-mercaptoethanol was added to a final concentration of 5\%. Equal amounts of protein were resolved (50 $\mu \mathrm{g}$ per lane) on $10 \%-12 \%$ sodium dodecyl sulfatepolyacrylamide gel electrophoresis gels and subsequently electrotransferred through a semi-dry transfer apparatus (Trans-Blot ${ }^{\circledR}$ SD; Bio-Rad, Hercules, CA, USA) onto a nitrocellulose membrane. Then, the nitrocellulose membrane was incubated for 60 minutes at $4^{\circ} \mathrm{C}$ in blocking solution (Tris-buffered saline containing 5\% nonfat milk and $0.1 \%$ Tween 20, $\mathrm{pH}=7.4$ ) and further incubated with the appropriate primary antibody dissolved in the blocking solution overnight at $4^{\circ} \mathrm{C}$. Primary antibodies against the following proteins were used: anti-ERK1/2 (1:1,000; Cell Signaling, Danvers, MA, USA), anti-p38 (1:1,000; Cell Signaling), and anti-JNK (1:1,000; Invitrogen, Thermo Fisher Scientific, Waltham, MA, USA). After washing, the membranes were incubated with adjusted secondary antibodies coupled to horseradish peroxidase $(1: 1,000)$ for 2 hours. The immunocomplexes were visualized by using a chemiluminescence detection system on X-ray films (Kodak ${ }^{\mathrm{TM}}$; PerkinElmer). Finally, films were scanned, and band density measurements were taken by using ImageJ software. Data were presented as the ratio of phosphorylated protein to the total protein. Uniform gel loading was confirmed with $\beta$-actin $(1: 1,000$; Abcam, Cambridge, UK) as the standard.

\section{Quantification of $\alpha$-bis in the lung}

To determine the levels of $\alpha$-bis in the lung tissue, a reversephase HPLC analysis was performed. Briefly, 18 hours after the LPS instillation, the animals were killed by anesthetic overdose (sodium pentobarbital, $500 \mathrm{mg} \mathrm{kg}{ }^{-1}$, IP) and perfused with saline, and the lung tissues were rapidly removed and weighed. Then, $3 \mathrm{~mL}$ of acetonitrile was added to extract the drug. The mixtures were centrifuged at $3,000 \times g$ for 10 minutes, and the supernatant was filtered $(0.45 \mu \mathrm{M}$; Merck Millipore) and injected $(20 \mu \mathrm{L})$ into the HPLC. The system consisted of a UVVis detector, a pump, and an S200 auto-injector (PerkinElmer), a guard column, and a Nova-Pak C18 column (150 mm, 4.9 $\mathrm{mm}, 4 \mu \mathrm{m}$; Waters). The mobile phase consisted of acetonitrile/ water $(60: 40, \mathrm{v} / \mathrm{v})$ adjusted to an apparent $\mathrm{pH}$ of $4.5 \pm 0.5$ with $10 \%(\mathrm{v} / \mathrm{v})$ acetic acid. $\alpha$-bis was detected at $207 \mathrm{~nm}$ with a retention time of 11 minutes. The HPLC method was validated to consider the linearity, interday and intraday variability, selectivity, accuracy, limit of quantification, and recovery. Linear calibration curves for $\alpha$-bis dissolved in acetonitrile 
were obtained in the range of $2.00-25.00 \mu \mathrm{g} \mathrm{mL}^{-1}$, presenting correlation coefficients $>0.99$. The limit of quantification was $2.00 \mu \mathrm{g} \mathrm{mL}^{-1}$. The area under the peak was calculated by using numerical integration. The quantity of $\alpha$-bis was calculated by comparing the peak area ratio from tissue samples of treated animals with those of the corresponding concentration standards of $\alpha$-bis in acetonitrile.

\section{Statistical analysis}

The results were presented as the mean \pm standard error of mean (SEM) of at least 6 animals per group. Statistical analysis was performed by one-way analysis of variance (ANOVA) followed by a Tukey's post hoc test by using GraphPad Prism software Version 5.01 (GraphPad Software, La Jolla, CA, USA). Two-way ANOVA was also performed followed by a Bonferroni posttest for lung function analyses. $P$-values $<0.05$ were considered statistically significant for both the tests.

\section{Results \\ Physicochemical characterization of $\alpha$-bis-LNCs}

The LNCs formulations were prepared by interfacial polymer deposition without requiring subsequent purification. $\alpha$-bis-LNCs and ULNCs were macroscopically homogeneous white turbid solutions presenting a bluish white opalescent effect. After preparation, the $\alpha$-bis-LNCs showed a hydrodynamic mean diameter of $160 \pm 10 \mathrm{~nm}$, a PDI of $0.10 \pm 0.06$, a zeta potential of $-8.1 \pm 1.0 \mathrm{mV}$, and a $\mathrm{pH}$ of $6.2 \pm 0.3$. Similar results were obtained for ULNCs, that is, particle size, PDI, zeta potential, and $\mathrm{pH}$ values were $168 \pm 5 \mathrm{~nm}, 0.11 \pm 0.08,-7.9 \pm 1.2 \mathrm{mV}$, and $6.05 \pm 0.5$, respectively. The formulations showed stable unimodal size distributions and PDIs $<0.12$, indicating narrow size distributions. $\alpha$-bis content was $10.03 \pm 0.06 \mathrm{mg} \mathrm{mL}^{-1}$, and the encapsulation efficiency was $99.78 \% \pm 1.8 \%$ for all the batches. Table 1 presents these results.

\section{Effect of $\alpha$-bis-LNCs on LPS-induced pulmonary elastance and AHR}

Invasive measurements of lung elastance after inhalation of methacholine (3-27 $\mathrm{mg} \mathrm{mL}^{-1}$ ) were taken 18 hours after the LPS instillation to assess the effect of the $\alpha$-bis-LNCs on changes in lung function. The inflammatory response caused by LPS led to AHR as determined by increased lung elastance after the methacholine challenge compared with the control group of saline-challenged mice (Figure 1). Administered 4 hours before provocation, $\alpha$-bis-LNCs (30, 50, and $100 \mathrm{mg} \mathrm{kg}^{-1}$ ) abolished LPS-induced AHR, whereas not all the three doses of the free drug modulated the AHR. It is important to note that at lesser treatment times ( 1 or 2 hours) neither free $\alpha$-bis nor the $\alpha$-bis-LNCs were able to significantly reduce the AHR (data not shown). The animals treated with unloaded nanocapsules showed no significant difference when compared to animals challenged with LPS.

\section{Effect of $\alpha$-bis-LNCs on inflammatory cell migration in the BALF}

To evaluate the effect of $\alpha$-bis-LNCs on LPS-induced leukocyte influx into the lungs, the animals were treated 4 hours before provocation. As expected, mice exposed to LPS showed a substantial increase in the total leukocyte cell numbers in the BALF, which was primarily due to the accumulation of neutrophils (Figure 2A). $\alpha$-bis-LNCs (30, 50 , and $100 \mathrm{mg} \mathrm{kg}^{-1}$ ) treatment abolished the neutrophil accumulation in the BALF (Figure 2A), which was confirmed by the quantification of MPO levels in lung tissue samples (Figure 2B). Only the highest dose of free $\alpha$-bis $\left(100 \mathrm{mg} \mathrm{kg}^{-1}\right)$ decreased the activity of MPO, as indicated by MPO quantification (Figure 2B). In addition, animals treated with drug-unloaded nanocapsules showed no significant difference when compared to animals challenged with LPS. It is important to note that at earlier treatment times ( 1 or 2 hours) neither free $\alpha$-bis nor $\alpha$-bis-LNCs were able to significantly reduce the total and differential cell counts in the BALF (data not shown).

\section{Effects of $\alpha$-bis-LNCs on cytokine levels in lung tissue}

We quantified the cytokine levels in the lung tissue to investigate the $\alpha$-bis-LNCs activity on inflammatory mediators. The lung tissue levels of MIP-2 and KC were significantly increased in mice stimulated with LPS compared with the saline group (Figure 3A and B). Mice subjected to oral treatment with $\alpha$-bis-LNCs (30-100 $\mathrm{mg} \mathrm{kg}^{-1}$ ) exhibited

Table I Physicochemical characteristics of $\alpha$-bis-LNCs and ULNCs

\begin{tabular}{|c|c|c|c|c|c|c|}
\hline Formulation & Size $(\mathbf{n m})$ & PDI & $\zeta$ potential $(\mathrm{mV})$ & $\mathrm{pH}$ & $\alpha$-bis content $\left(\mathrm{mg} \mathrm{mL}^{-1}\right)$ & Encapsulation (\%) \\
\hline$\alpha$-bis-LNCs & $160 \pm 10$ & $0.10 \pm 0.06$ & $-8.1 \pm 1.0$ & $6.2 \pm 0.3$ & $10.03 \pm 0.06$ & $99.78 \pm 1.8$ \\
\hline ULNCs & $168 \pm 5$ & $0.1 I \pm 0.08$ & $-7.9 \pm 1.2$ & $6.05 \pm 0.5$ & NA & NA \\
\hline
\end{tabular}

Note: Data presented as mean \pm standard deviation.

Abbreviations: $\alpha$-bis, $\alpha$-bisabolol; $\alpha$-bis-LNCs, $\alpha$-bis-loaded LNCs; LNCs, lipid-core nanocapsules; ULNCs, drug-unloaded nanocapsules; NA, not applicable; PDI, polydispersity index. 


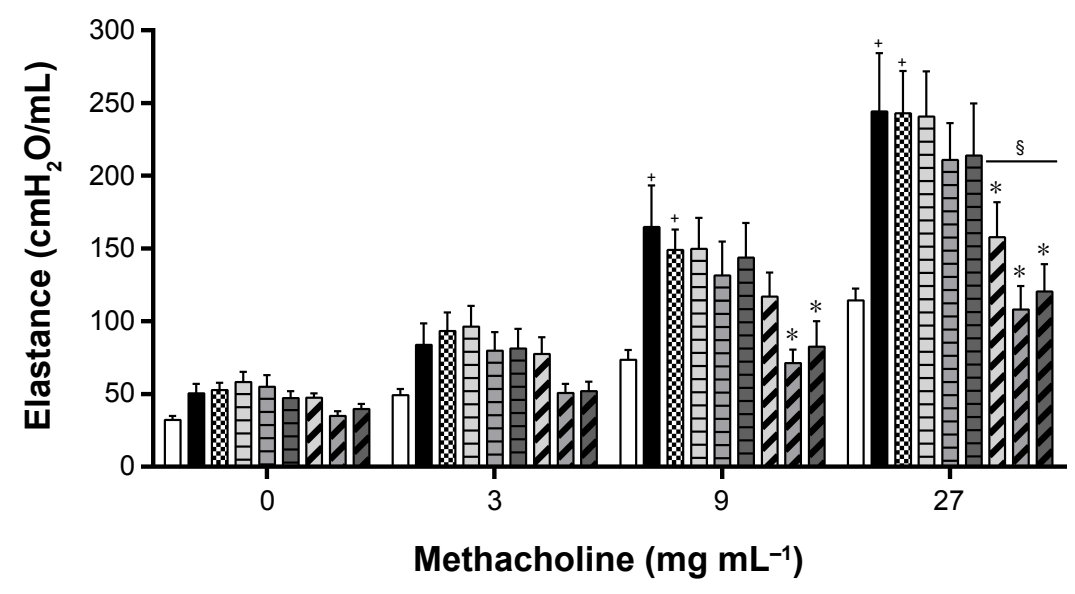

\begin{tabular}{|c|c|c|c|}
\hline$\square$ & LPS & $\mathbf{\infty}$ & LPS + ULNCs \\
\hline$\square$ & LPS $+\alpha$-bis $30 \mathrm{mg} \mathrm{kg}^{-1}$ & 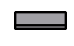 & LPS $+\alpha$-bis $50 \mathrm{mg} \mathrm{kg}^{-1}$ \\
\hline & LPS $+\alpha$-bis $100 \mathrm{mg} \mathrm{kg}^{-1}$ & $\mathbb{Z Z}$ & LPS $+\alpha$-bis-LNCs $30 \mathrm{mg} \mathrm{kg}^{-1}$ \\
\hline 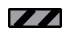 & LPS $+\alpha$-bis-LNCs 50 mg kg-1 & $\mathbb{Z Z}$ & LPS $+\alpha$-bis-LNCs $100 \mathrm{mg} \mathrm{kg}^{-1}$ \\
\hline
\end{tabular}

Figure I Effect of treatment with $\alpha$-bis-LNCs in pulmonary elastance and airway hyperresponsiveness induced by LPS.

Notes: The animals were pretreated orally with $\alpha$-bis, $\alpha$-bis-LNCs $\left(30,50\right.$, or $\left.100 \mathrm{mg} \mathrm{kg}{ }^{-1}\right)$, or ULNCs. After 4 hours, the mice were anesthetized and challenged intranasally with LPS $(25 \mu \mathrm{g} / 25 \mu \mathrm{L})$ or vehicle. Airway responsiveness was measured by changes in airway elastance after aerosolization of methacholine 18 hours after LPS instillation. Data are expressed as the mean \pm SEM $(n=5-7)$. ${ }^{+} P<0.05$ compared with the saline group; ${ }^{*} P<0.05$ compared with the LPS-induced group; $\$ P<0.05$ compared with respective $\alpha$-bis doses. Abbreviations: $\alpha$-bis, $\alpha$-bisabolol; $\alpha$-bis-LNCs, $\alpha$-bisabolol-loaded lipid-core nanocapsules; LNCs, lipid-core nanocapsules; ULNCs, drug-unloaded nanocapsules; LPS, lipopolysaccharide; SEM, standard error of mean.

clearly reduced LPS-induced changes in MIP-2 and KC. In contrast, free $\alpha$-bis failed to modify $\mathrm{KC}$ and inhibited MIP-2 levels only at the highest dose $\left(100 \mathrm{mg} \mathrm{kg}^{-1}\right)$. No significant alteration in cytokine levels of animals treated with the ULNCs formulation was observed.

A

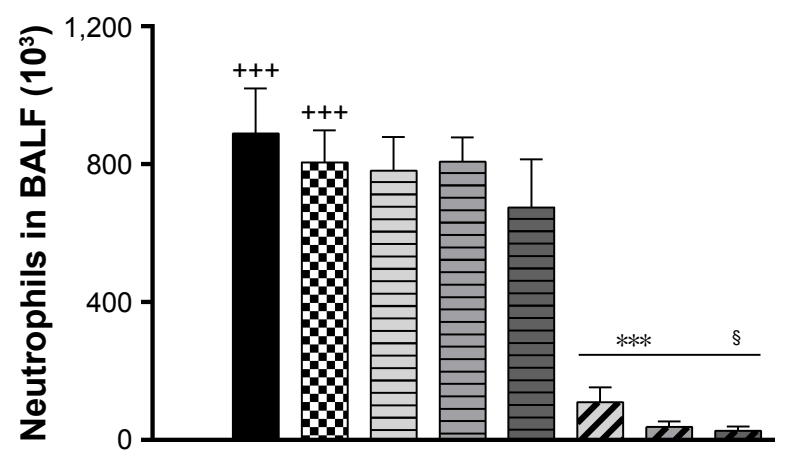

\section{Effects of $\alpha$-bis-LNCs on histological changes in lung tissues}

To assess histological alterations in lung tissue, lung sections obtained 18 hours after the administration of LPS were subjected to H\&E staining. In the LPS group, the lung showed significant

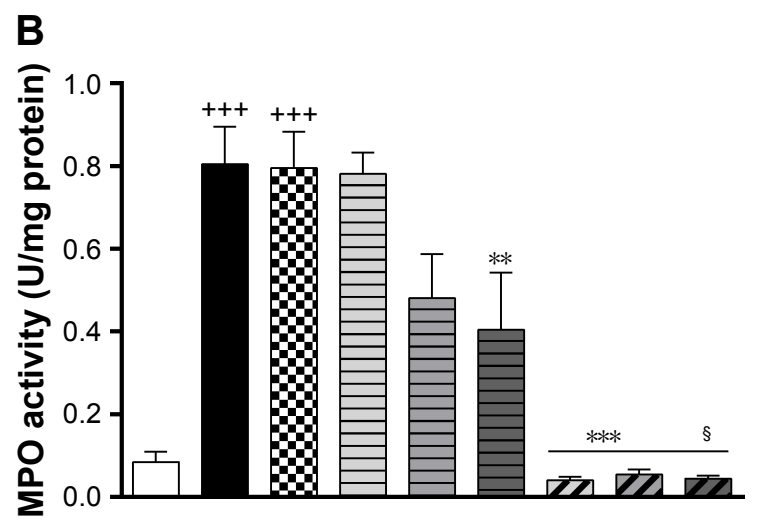

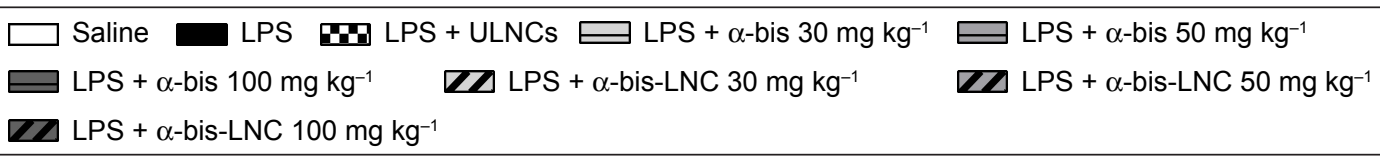

Figure 2 Effect of treatment with $\alpha$-bis-LNCs on migration of neutrophils in bronchoalveolar lavage fluid.

Notes: The mice were treated with $\alpha$-bis, $\alpha$-bis-LNCs $\left(30,50\right.$, or $\left.100 \mathrm{mg} \mathrm{kg}^{-1}\right)$, or ULNCs 4 hours before LPS or saline instillation. The bronchoalveolar lavage was performed with PBS + EDTA 18 hours later to collect cells. Then, the lungs were perfused and collected to measure MPO activity. (A) Neutrophils and (B) myeloperoxidase activity. Data are expressed as the mean \pm SEM $(n=5-7)$. ${ }^{++} P<0.00$ I compared with the saline group; $* * P<0.01$ and $* * * P<0.001$ compared with the LPS-induced group; $\S p<0.05$ compared with $\alpha$-bis.

Abbreviations: $\alpha$-bis, $\alpha$-bisabolol; $\alpha$-bis-LNCs, $\alpha$-bisabolol-loaded lipid-core nanocapsules; LNCs, lipid-core nanocapsules; BALF, bronchoalveolar lavage fluid; ULNCs, drug-unloaded nanocapsules; LPS, lipopolysaccharide; MPO, myeloperoxidase; SEM, standard error of mean. 

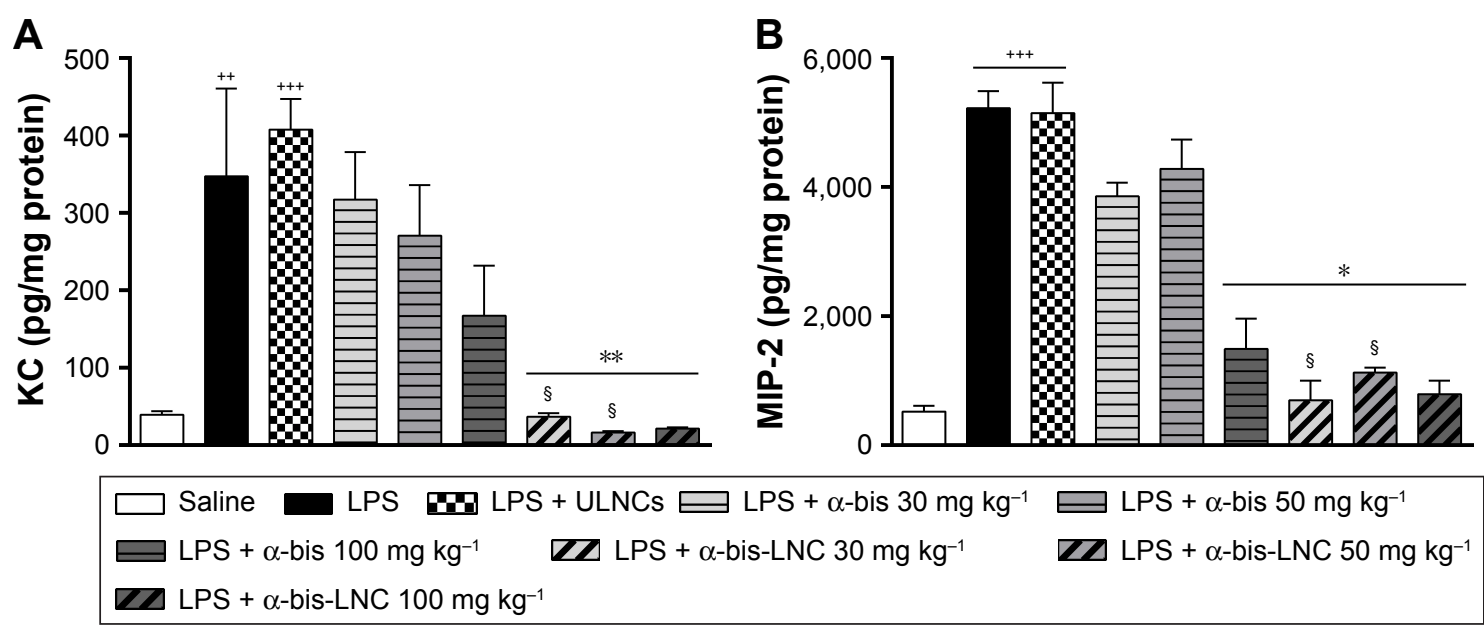

Figure 3 Effect of treatment with $\alpha$-bis-LNCs on chemokine levels.

Notes: The mice were treated with $\alpha$-bis, $\alpha$-bis-LNCs $\left(30,50\right.$, or $\left.100 \mathrm{mg} \mathrm{kg}^{-1}\right)$, or ULNCs 4 hours before LPS or saline instillation. The lungs were perfused and collected to measure levels of $(\mathbf{A}) \mathrm{KC}$ and $(\mathbf{B})$ MIP-2 by ELISA. Data are expressed as the mean \pm SEM $(n=5-7)$. ${ }^{+} P<0.0 \mathrm{I}$ and ${ }^{++} \mathrm{P}<0.00 \mathrm{I}$ compared with the saline group; ${ }^{* * P}<0.0 \mathrm{I}$ compared with the LPS-induced group; $* P<0.05$ compared with the LPS-treated group; $\$ P<0.05$ compared with $\alpha$-bis.

Abbreviations: $\alpha$-bis, $\alpha$-bisabolol; $\alpha$-bis-LNCs, $\alpha$-bisabolol-loaded lipid-core nanocapsules; LNCs, lipid-core nanocapsules; ELISA, enzyme-linked immunosorbent assay; ULNCs, drug-unloaded nanocapsules; LPS, lipopolysaccharide; SEM, standard error of mean.

pathologic changes, such as alveolar wall thickening, inflammatory cell infiltration, alveolar hemorrhage, and lung tissue damage. These changes were analyzed by a semiquantitative rating following a histological score system. The analysis showed the establishment of an acute inflammatory process in the lungs of mice challenged with LPS, which was not modified by any of the three doses of free $\alpha$-bis. On the other hand, treatment with the $\alpha$-bis-LNCs at doses of 30, 50, and $100 \mathrm{mg} \mathrm{kg}^{-1}$ (Figure 4A and B) significantly reduced the lung injury in the tissue.

\section{Mechanisms involved in the anti- inflammatory effects of $\alpha$-bis-LNCs}

In order to elucidate the cell signaling involved in the antiinflammatory effects of $\alpha$-bis, a Western blotting assay was performed on lung tissue samples from animals pretreated with either free $\alpha$-bis or $\alpha$-bis-LNCs at a dose of $50 \mathrm{mg} \mathrm{kg}^{-1} 18$ hours after LPS challenge. LPS stimulation induced phosphorylation of ERK, p38, and JNK in lung tissue from untreated mice (Figure 5A-C). Treatment with free $\alpha$-bis failed to reduce the levels of pERK, p-p38, or pJNK. However, animals treated with $\alpha$-bis-LNCs (Figure 5A-C) presented a significant inhibition of ERK, p38, and JNK phosphorylation/activation without modifying the total levels of the proteins. The animals treated with the ULNCs formulation showed no significant difference compared with animals challenged with LPS.

\section{Lipid-core nanocapsules increase the $\alpha$-bis concentration in lung tissue}

Because treatment with drug-loaded LNCs was observed to enhance the effectiveness of $\alpha$-bis against LPS-induced inflammation, we hypothesized that the LNCs could facilitate these improvements by increasing the lung biodistribution of $\alpha$-bis. Therefore, quantitative analyses were performed to assess the lung biodistribution of $\alpha$-bis administered as either $\alpha$-bis-LNCs or free $\alpha$-bis at the same doses. As shown in Figure 6 , a significantly higher quantity of $\alpha$-bis was measured in the lungs of animals treated with $\alpha$-bis-LNCs compared with animals treated with free $\alpha$-bis. Increases of 6,16 , and 20 times for the doses of 30,50 , and $100 \mathrm{mg} \mathrm{kg}^{-1}$, respectively, were observed while comparing the nanoencapsulated and the free drug (Figure 6).

\section{Discussion}

Massive pulmonary infiltration by neutrophils associated with disruption of the alveolar/endothelial barrier and plasma leakage is the underlying component in ARDS, and thus, the development of therapeutics that inhibit tissue neutrophil accumulation is of considerable interest. ${ }^{32,33}$ Using a murine model of ALI, we demonstrated in this study that $\alpha$-bis-LNCs abolished LPS-induced neutrophil recruitment into the lung and prevented the subsequent AHR 18 hours postchallenge. In parallel, it inhibited the generation of proinflammatory chemokines and the phosphorylation/activation of ERK, p38, and JNK in the lung tissue. Finally, HPLC measurements clearly detected higher concentrations of $\alpha$-bis in lung tissue samples from mice treated with $\alpha$-bis-LNCs compared with those receiving free $\alpha$-bis, indicating that the nanoformulation was able to increase the bioavailability of the $\alpha$-bis.

Nanocapsules are one of the most studied delivery systems to protect against degradation, enhance solubility, 

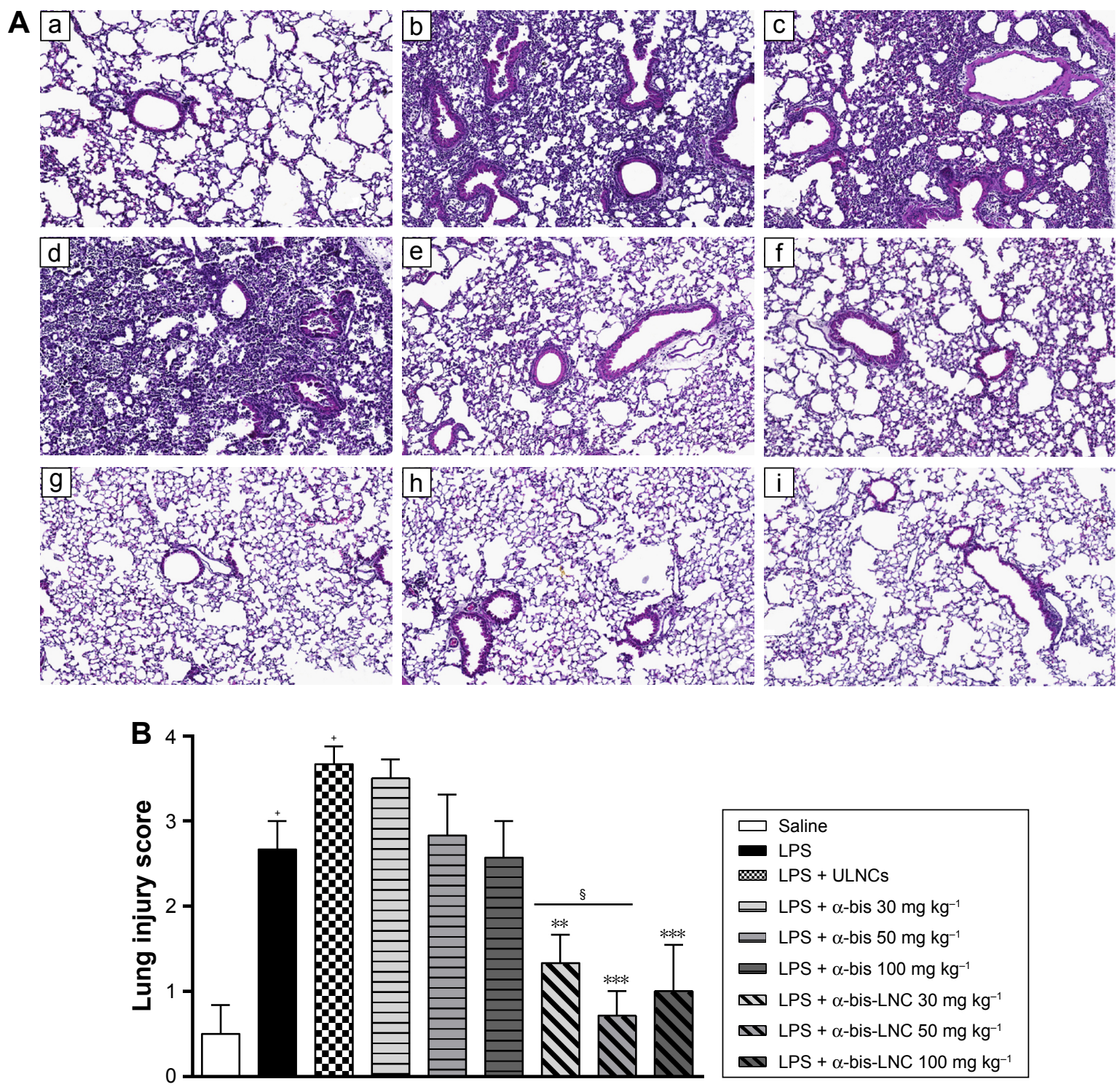

Figure 4 Effect of treatment with $\alpha$-bis-LNCs on tissue damage.

Notes: The mice were treated with $\alpha$-bis, $\alpha$-bis-LNCs $\left(30,50\right.$, or $\left.100 \mathrm{mg} \mathrm{kg}^{-1}\right)$, or ULNCs 4 hours before LPS or saline instillation. The lungs were perfused and collected in formalin. Lung serial sections were embedded in paraffin by routine methods and stained with H\&E. (A) Microscopic analysis of stained tissue sections: a, saline; b, LPS; c, LPS + ULNCs; d, $\alpha$-bis $30 \mathrm{mg} \mathrm{kg}^{-1}$; e, $\alpha$-bis $50 \mathrm{mg} \mathrm{kg}^{-1}$, f, $\alpha$-bis $100 \mathrm{mg} \mathrm{kg}^{-1} ;$ g, $\alpha$-bis-LNC $30 \mathrm{mg} \mathrm{kg}^{-1} ;$ h, $\alpha$-bis-LNC $50 \mathrm{mg} \mathrm{kg}^{-1} ;$ i, $\alpha$-bis-LNC $100 \mathrm{mg} \mathrm{kg}^{-1} ; 10 \times \mathrm{magnification}$. (B) Histological analysis of lung inflammation by a scoring system. Data are expressed as the mean $\pm S E M(n=5-7)$. $P<0.05$ compared with the saline group; **P $<0.01$, and $* * * P<0.001$ compared with the LPS-induced group; $\$ P<0.05$ compared with $\alpha$-bis.

Abbreviations: $\alpha$-bis, $\alpha$-bisabolol; $\alpha$-bis-LNCs, $\alpha$-bisabolol-loaded lipid-core nanocapsules; LNCs, lipid-core nanocapsules; ULNCs, drug-unloaded nanocapsules; LPS, lipopolysaccharide; SEM, standard error of mean.

and facilitate higher biological uptake of drugs. Especially, polymeric nanocapsules provide a slower release of the drug due to the formation of reservoir behavior, controlling drug release. The interfacial deposition of preformed polymer is one of the most effective methods for the preparation of nanocapsule formulations, particularly to carry lipophilic drugs. ${ }^{21-26,34}$ Injection of the organic phase into the aqueous phase creates a colloidal suspension solution with a pearly white bluish color. This bluish color is due to the Tyndall effect, which is observed when light is scattered by the fine particles dispersed in water. The mechanisms of encapsulation and release of several drugs from nanoparticle-based systems have been extensively studied by our group. ${ }^{25,35-38}$ Here, the high $\alpha$-bis loading capacity of LNCs was a consequence of its concomitant use as a core constituent and active ingredient, leading to an apparent solubility in water of $\sim 10 \mathrm{mg} \mathrm{mL}^{-1}$ in the $\alpha$-bis-LNCs.

The intranasal instillation of endotoxin, an LPS that forms an integral part of the cell wall of specific strains of gram-negative bacteria, has been largely used to mimic several aspects of ARDS in mice. ${ }^{32,33,39}$ LPS acts via Toll-like receptor 4 (TLR4) to increase the levels of inflammatory 
A
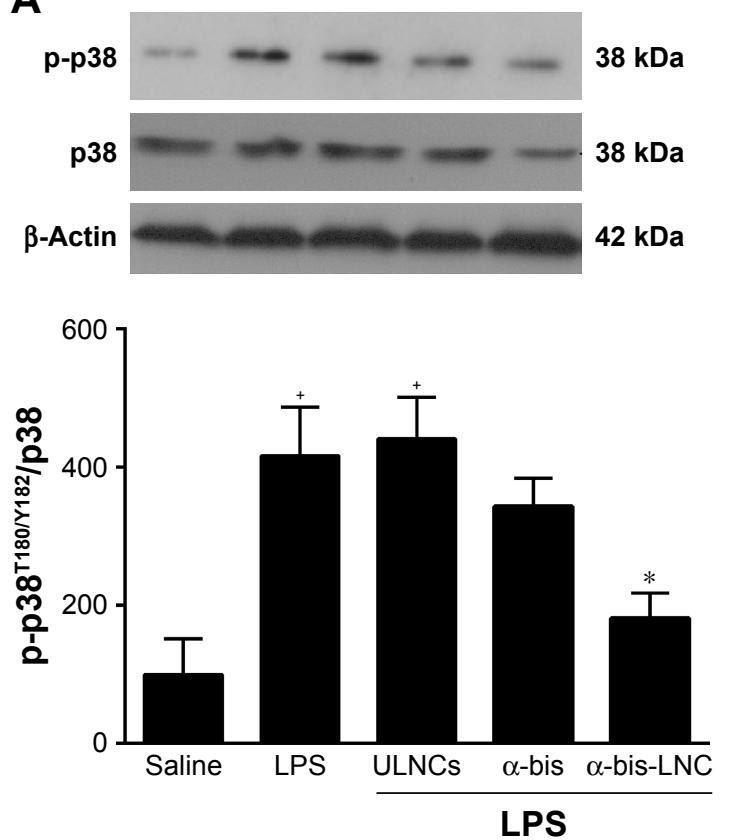

B
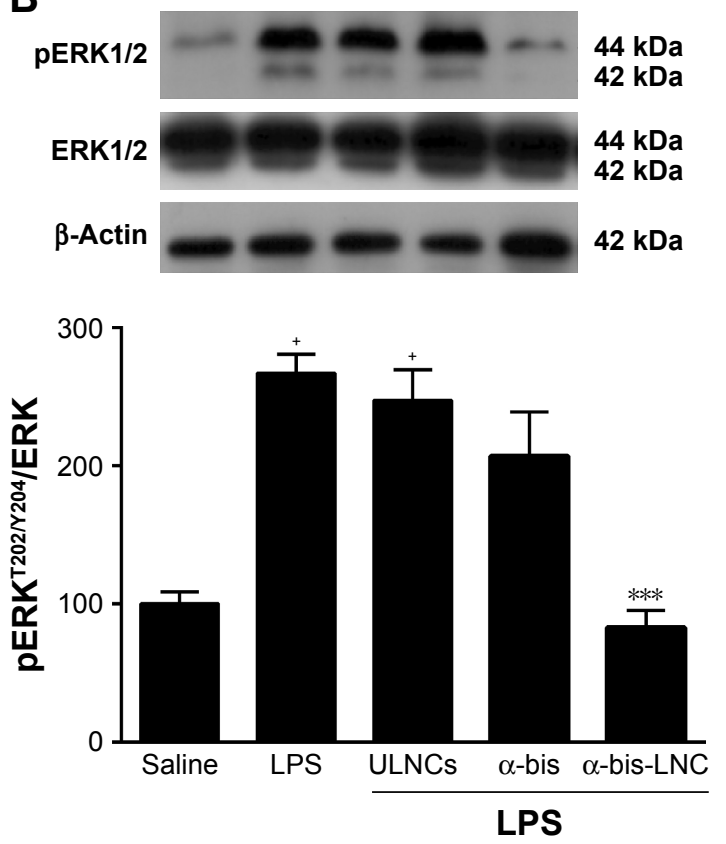

C
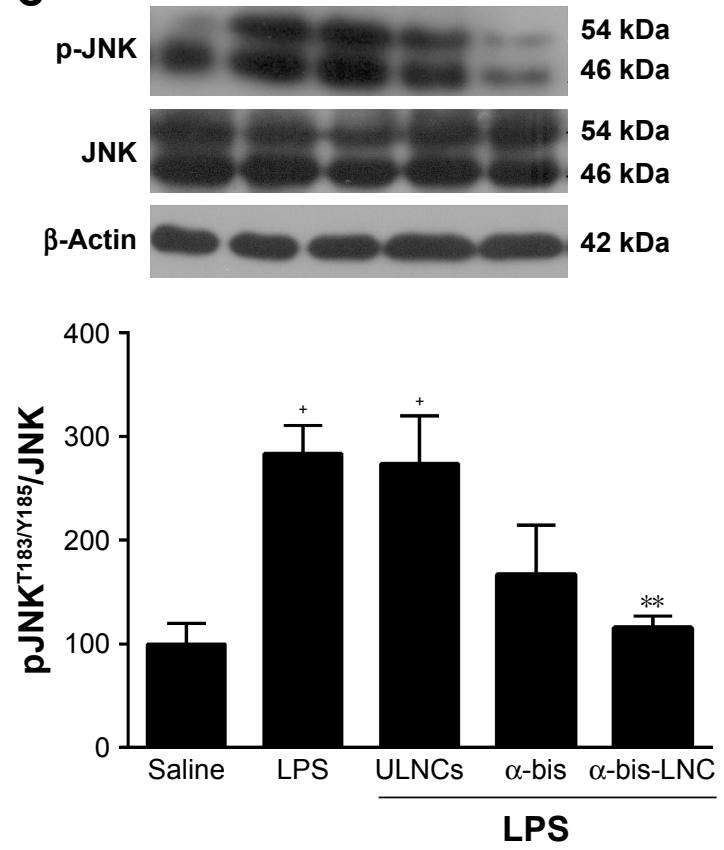

Figure 5 Effect of treatment with $\alpha$-bis-LNCs on MAPK pathway activation.

Notes: The lungs were perfused and collected to analyze protein expression 18 hours after LPS challenge and the pretreatment with $\alpha$-bis, $\alpha$-bis-LNCs, or ULNCs at a dose of $50 \mathrm{mg} \mathrm{kg}^{-1}$. Representative Western blotting analysis of the phosphorylation state of (A) p38, (B) ERKI/2, and (C) JNK. The densitometric values obtained for phosphorylated and total protein from treatments were normalized to their respective controls that were not exposed to LPS (control bar; I00\%). Data are expressed as a ratio of the normalized percentages of phosphorylated and total protein. Bars represent the mean $\pm S E M(n=5-7)$. ${ }^{+} P<0.05$ compared with the saline group; $* P<0.05$, $* * P<0.01$, and $* * * P<0.001$ compared with the LPS-induced group.

Abbreviations: $\alpha$-bis, $\alpha$-bisabolol; $\alpha$-bis-LNCs, $\alpha$-bisabolol-loaded lipid-core nanocapsules; LNCs, lipid-core nanocapsules; ULNCs, drug-unloaded nanocapsules; LPS, lipopolysaccharide; MAPK, mitogen-activated protein kinase; SEM, standard error of mean.

cytokines and chemokines in the lung tissue, leading to neutrophil recruitment, edema, and diffuse alveolar damage..$^{40-42}$ Furthermore, airway smooth muscles present from the bronchial tree up to the terminal bronchioles are highly activated during inflammation and lung tissue damage with engagement of TLRs promoting nonspecific airway hyperresponsiveness. Therefore, LPS instillation provides a useful experimental system for investigating the mechanisms of AHR in anesthetized and ventilated mice. ${ }^{43-45}$ However, it is important to reinforce that, although animal models provide a 


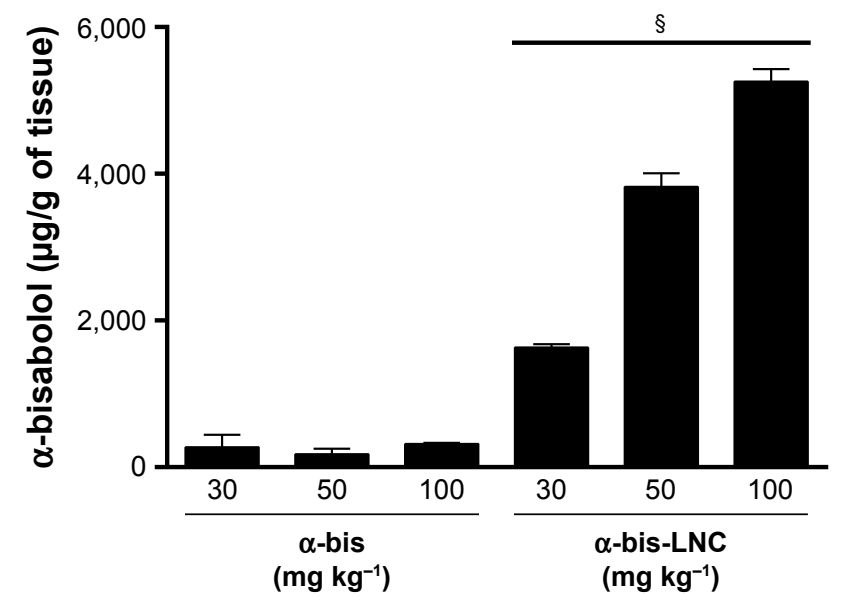

Figure 6 Quantification of $\alpha$-bis in lung tissue.

Notes: The amount of pulmonary $\alpha$-bis was analyzed by using high-performance liquid chromatography in mice treated with $\alpha$-bis or $\alpha$-bis $\operatorname{LNCs}(30,50$, or $100 \mathrm{mg} \mathrm{kg}^{-1}$ ) and challenged with LPS. The $\alpha$-bis amount was expressed by $\mu \mathrm{g}$ of $\alpha$-bis per gram of lung tissue. Data are expressed as the mean $\pm \operatorname{SEM}(n=5-7)$. $\S P<0.05$ compared with the respective doses of $\alpha$-bis.

Abbreviations: $\alpha$-bis, $\alpha$-bisabolol; $\alpha$-bis-LNCs, $\alpha$-bisabolol-loaded lipidcore nanocapsules; LNCs, lipid-core nanocapsules; LPS, lipopolysaccharide; SEM, standard error of mean.

bridge between clinical and the laboratory research, no single animal model reproduces complete characteristics of ARDS, and most of the existing experimental models are relevant for limited aspects of known clinical situations. In order to mimic human ARDS reliably, an animal model should reproduce the acute injury to the epithelial and endothelial barriers in the lungs together with the acute inflammatory responses. Ideally, the injury should evolve over the time if the animals are maintained in that condition for prolonged periods. In addition, LPS model has some drawbacks; LPS preparations vary in purity and can be contaminated with bacterial lipoproteins and other bacterial materials.

To the best of our knowledge, this work is the first to show the anti-inflammatory effects of nanoencapsulated $\alpha$-bis against LPS-induced ALI. We demonstrated that $\alpha$-bis can modulate LPS-induced hyperresponsiveness in an ARDS model by improving the lung function triggered by pretreatment with $\alpha$-bis-LNCs, as observed by the decrease in lung elastance after a methacholine challenge. Consistent with our results, Siqueira et $\mathrm{al}^{46}$ have shown that tracheal rings of rats challenged with ovalbumin and treated previously with $\alpha$-bis (aerosol) reduced the hyperresponsive phenotype, and they showed that $\alpha$-bis may act as an inhibitor of voltagedependent $\mathrm{Ca}^{2+}$ channels. Similarly, Roberts et al, ${ }^{47}$ using a porcine isolated tissue bath (from coronary and splenic arteries), demonstrated that $\alpha$-bis was able to inhibit calciuminduced contractions and that the removal of extracellular calcium inhibited its responses.
One of the more important features of lung inflammation is the increase in leukocyte migration. ${ }^{48,49}$ In this scenario, neutrophils, combined with a myriad of mediators, play a central role in the pathogenesis of ALI/ARDS. ${ }^{50,51}$ After intranasal LPS instillation, neutrophils migrated across the endothelium and epithelium into the alveolar space, and then, they were activated, leading to excessive production of reactive oxygen species and the release of granular enzymes, such as MPO, and cytotoxic and proinflammatory mediators. ${ }^{52,53}$ In the present study, the exposure of mice of the strain A/J to LPS led to a marked increase in the influx of neutrophils into the bronchoalveolar space. Augmented levels of MPO activity in lung tissue homogenates reinforce the predominance of neutrophils in the leukocyte infiltrate. Additionally, the response to LPS was marked by AHR to the bronchoconstrictor methacholine. The inflammatory profile triggered by LPS was not modified by pretreatment with free $\alpha$-bis. In contrast, the animals pretreated with $\alpha$-bis-LNCs presented a marked decrease in neutrophil migration into the lungs, which was in agreement with the lower amount of MPO. In support of these findings, a study using extracts from Matricaria recutita L., in which the main constituents of the oil are $\alpha$-bis and its oxides, suppressed leukocyte infiltration induced by simultaneous injection of carrageenan and prostaglandin E1 in "Wistar" rats. ${ }^{54}$ Similarly, treatment with $\alpha$-bis decreased the migration of leukocytes to peritoneal cavities after IP application of carrageenan in rats. In the same study, the molecule was able to significantly decrease the MPO activity in the peritoneal fluid of rats with induced peritonitis as well as in an in vitro assay of neutrophil degranulation by using phorbol-myristate-acetate. ${ }^{55}$

MIP-2, also known as CXCL2, and $\mathrm{KC}$ were reported as being important chemoattractant factors to draw neutrophils to the site of inflammation. ${ }^{56-58}$ Regarding the effects of $\alpha$-bis on the production of proinflammatory cytokines, the free form was able to reduce the MIP-2 level only at the highest tested dose. However, in line with the results so far described, the $\alpha$-bis-LNCs formulation lowered the levels of all measured cytokines at the three tested doses. In addition, the histological changes reflected the inflammatory processes triggered by LPS in lung tissue. We have shown that $\alpha$-bis was able to attenuate tissue injury, primarily alveolar wall thickening, and inflammatory cell infiltration, only when administered as $\alpha$-bis-LNCs. Our results showed that the effectiveness of the treatment was only achieved because of nanoencapsulation of $\alpha$-bis in LNCs. These data further support the anti-inflammatory activity effect of $\alpha$-bis-LNCs. 
LPS can stimulate many intracellular signaling pathways, in particular mitogen-activated protein kinase (MAPK) signaling, which is related to the release of several proinflammatory cytokines, such as KC and MIP-2,,$^{59,60}$ mediators implicated in ARDS pathogenesis. ${ }^{61-64}$ In addition, it has been documented that MAPKs are involved in the inflammatory response in lung injury. ${ }^{65}$ Considering these data, efforts were made to improve our understanding at the molecular level of the possible effects of $\alpha$-bis on this pathway. We observed a significant reduction in the phosphorylation levels of ERK1/2, JNK, and p38 proteins in the lungs when the animals were treated with $\alpha$-bis-LNCs at a dose of $50 \mathrm{mg} \mathrm{kg}{ }^{-1}$, indicating a modulation of MAPK signaling. The same dose of free $\alpha$-bis was not able to significantly reduce the phosphorylation levels of ERK1/2, JNK, and $\mathrm{p} 38$. Comparable results were found by Kim et $\mathrm{a}^{166}$ who used a peritoneal macrophage cell line (RAW264.7) to show that $\alpha$-bis was able to inhibit the activation of ERK $1 / 2$ and $\mathrm{p} 38$; however, it was ineffective in inhibiting JNK.

Considering the significant results obtained with nanoencapsulated $\alpha$-bis and to confirm our hypothesis that the use of nanotechnology would lead to improved $\alpha$-bis action by increasing its bioavailability, we quantified $\alpha$-bis in lung tissues. It was observed that animals treated with $\alpha$-bisLNCs (4 hours prior to the challenge with LPS) had higher amounts of $\alpha$-bis in lung tissue challenge compared with the amount observed in the lungs of animals treated with free $\alpha$-bis 18 hours after the administration of LPS. Therefore, the drug formulation $\alpha$-bis-LNCs is advantageous due to the protection provided by the nanocapsules, which minimizes metabolism and may result in higher amounts of the drug absorbed by the oral route and distributed to the tissues according to the biopharmaceutical properties of the LNCs, improving the efficacy of treatment. Additionally, nanoencapsulation leads to an increase in the half-life of lipophilic drugs primarily through gradual and sustained release. ${ }^{26}$ The lack of free $\alpha$-bis efficacy can also be explained by lower amounts of drug reaching the lungs, in subpharmacological doses. Furthermore, the delivery of $\alpha$-bis into lung tissue promoted by nanocapsules might be due to the enhanced permeability and retention effect triggered by inflammation present in the ARDS model. However, the mechanisms involved in directing the nanoparticles are not fully elucidated and will be targets for future research.

\section{Conclusion}

Taken together, we suggest that pretreatment with $\alpha$-bisLNCs has an anti-inflammatory effect in an acute lung inflammation model induced by LPS and that this effect is related, at least in part, to the inhibition of the MAPK pathway. Furthermore, nanoencapsulation of $\alpha$-bis proved to be crucial for the improved efficacy of the drug because the orally administered LNCs affected the amount of $\alpha$-bis in the lungs, increasing the local action against the inflammatory process. Therefore, our results provide a foundation for further investigations of nanoencapsulated $\alpha$-bis as a potential candidate for a new pharmacological strategy in the treatment of pulmonary inflammatory diseases such as ARDS.

\section{Acknowledgments}

This study was supported by the Brazilian agencies Conselho Nacional de Desenvolvimento Científico e Tecnológico (CNPq), Fundação Coordenação de Aperfeiçoamento de Pessoal de Nível Superior (CAPES), and Fundação de Amparo à Pesquisa do Estado do Rio de Janeiro (FAPERJ). APL D’Almeida, MT Pacheco de Oliveira, and D de Sá Coutinho were fellows from CAPES. CR Gomes and $\mathrm{T}$ Terroso were fellows from CNPq. ÉT de Souza was the recipient of an FAPERJ postdoctoral fellowship. BT Ciambarela was the recipient of a CAPES postdoctoral fellowship. The authors would like to thank Dr Rudimar Luiz Frozza for critically reviewing the manuscript.

\section{Disclosure}

The authors report no conflicts of interest in this work.

\section{References}

1. Arroliga AC, Ghamra ZW, Perez Trepichio A, et al. Incidence of ARDS in an adult population of northeast Ohio. Chest. 2002;121(6): 1972-1976.

2. Zilberberg MD, Epstein SK. Acute lung injury in the medical ICU: comorbid conditions, age, etiology, and hospital outcome. Am J Respir Crit Care Med. 1998;157(4 Pt 1):1159-1164.

3. Koh Y. Update in acute respiratory distress syndrome. J Intensive Care. 2014;2(1):2.

4. Ware LB, Matthay MA. The acute respiratory distress syndrome. NEngl J Med. 20004;342(18):1334-1349.

5. Boyle AJ, Mac Sweeney R, McAuley DF. Pharmacological treatments in ARDS; a state-of-the-art update. BMC Med. 2013;11:166.

6. Recio MC, Andujar I, Rios JL. Anti-inflammatory agents from plants: progress and potential. Curr Med Chem. 2012;19(14):2088-2103.

7. Pereira RL, Ibrahim T, Lucchetti L, da Silva AJ, Goncalves de Moraes VL. Immunosuppressive and anti-inflammatory effects of methanolic extract and the polyacetylene isolated from Bidens pilosa $\mathrm{L}$. Immunopharmacology. 1999;43(1):31-37.

8. Zakaria ZA, Patahuddin H, Mohamad AS, Israf DA, Sulaiman MR. In vivo anti-nociceptive and anti-inflammatory activities of the aqueous extract of the leaves of Piper sarmentosum. J Ethnopharmacol. 2010; 128(1):42-48.

9. Ojima I. Modern natural products chemistry and drug discovery. J Med Chem. 2008;51(9):2587-2588.

10. Balunas MJ, Kinghorn AD. Drug discovery from medicinal plants. Life Sci. 2005;78(5):431-441. 
11. Jakovlev V, Isaac O, Thiemer K, Kunde R. Pharmakologische Untersuchungen von Kamillen-Inhaltsstoffen - II. Neue Untersuchungen zur antiphlogistischen Wirkung des $(-)-\alpha-$ Bisabolols und der Bisabololoxide [Pharmacological investigations with compounds of chamomile ii. new investigations on the antiphlogistic effects of (-)-alpha-bisabolol and bisabolol oxides (author's transl)]. Planta Med. 1979;35(2):125-140. German.

12. Sadr Lahijani MS, Raoof Kateb HR, Heady R, Yazdani D. The effect of German chamomile (Marticaria recutita L.) extract and tea tree (Melaleuca alternifolia L.) oil used as irrigants on removal of smear layer: a scanning electron microscopy study. Int Endod J. 2006;39(3): 190-195.

13. Tomic M, Popovic V, Petrovic S, et al. Antihyperalgesic and antiedematous activities of bisabolol-oxides-rich matricaria oil in a rat model of inflammation. Phytother Res. 2014;28(5):759-766.

14. Vila R, Santana AI, Perez-Roses R, et al. Composition and biological activity of the essential oil from leaves of Plinia cerrocampanensis, a new source of alpha-bisabolol. Bioresour Technol. 2010;101(7): 2510-2514.

15. Rottini MM, Amaral AC, Ferreira JL, et al. In vitro evaluation of (-)alpha-bisabolol as a promising agent against Leishmania amazonensis. Exp Parasitol. 2015;148:66-72.

16. Cavalieri E, Mariotto S, Fabrizi C, et al. alpha-Bisabolol, a nontoxic natural compound, strongly induces apoptosis in glioma cells. Biochem Biophys Res Commun. 2004;315(3):589-594.

17. da Silva AP, Martini MV, de Oliveira CM, et al. Antitumor activity of (-)-alpha-bisabolol-based thiosemicarbazones against human tumor cell lines. Eur J Med Chem. 2010;45(7):2987-2993.

18. Die Kamille HS. Handbuch für Ärzte, Apotheker und andere Naturwissenschaftler. Stuttgart: Wissenschaftliche Verlagsgesellschaft; 1987.

19. Da Silva AL, Santos RS, Xisto DG, Alonso Sdel V, Morales MM, Rocco PR. Nanoparticle-based therapy for respiratory diseases. An Acad Bras Cienc. 2013;85(1):137-146.

20. Puri A, Loomis K, Smith B, et al. Lipid-based nanoparticles as pharmaceutical drug carriers: from concepts to clinic. Crit Rev Ther Drug Carrier Syst. 2009;26(6):523-580.

21. Jager E, Venturini CG, Poletto FS, et al. Sustained release from lipidcore nanocapsules by varying the core viscosity and the particle surface area. J Biomed Nanotechnol. 2009;5(1):130-140.

22. Ourique AF, Pohlmann AR, Guterres SS, Beck RC. Tretinoin-loaded nanocapsules: Preparation, physicochemical characterization, and photostability study. Int J Pharm. 2008;352(1-2):1-4.

23. Venturini CG, Jager E, Oliveira CP, et al. Formulation of lipid core nanocapsules. Colloids Sur APhysicochem Eng Asp. 2011;375:200-208.

24. Kashi TS, Eskandarion S, Esfandyari-Manesh M, et al. Improved drug loading and antibacterial activity of minocycline-loaded PLGA nanoparticles prepared by solid/oil/water ion pairing method. Int $J$ Nanomedicine. 2012;7:221-234.

25. Cruz L, Soares LU, Costa TD, et al. Diffusion and mathematical modeling of release profiles from nanocarriers. Int J Pharm. 2006; 313(1-2):198-205.

26. Mora-Huertas CE, Fessi H, Elaissari A. Polymer-based nanocapsules for drug delivery. Int J Pharm. 2010;385(1-2):113-142.

27. Szarka RJ, Wang N, Gordon L, Nation PN, Smith RH. A murine model of pulmonary damage induced by lipopolysaccharide via intranasal instillation. J Immunol Methods. 1997;202(1):49-57.

28. Kummerle AE, Schmitt M, Cardozo SV, et al. Design, synthesis, and pharmacological evaluation of $\mathrm{N}$-acylhydrazones and novel conformationally constrained compounds as selective and potent orally active phosphodiesterase-4 inhibitors. $J$ Med Chem. 2012;55(17): $7525-7545$.

29. Smith PK, Krohn RI, Hermanson GT, et al. Measurement of protein using bicinchoninic acid. Anal Biochem. 1958;150:76-85.

30. Hirano S. Migratory response of PMN after intraperitoneal and intratracheal administration of lipopolysaccharide. Am J Physiol. 1996;270: L836-L845.
31. Zhu T, Wang DX, Zhang W, et al. Andrographolide protects against LPS-induced acute lung injury by inactivation of NF-kappaB. PLoS One. 2013;8(2):e56407.

32. Chen H, Bai C, Wang X. The value of the lipopolysaccharide-induced acute lung injury model in respiratory medicine. Expert Rev Respir Med. 2010;4(6):773-783.

33. Brigham KL, Meyrick B. Endotoxin and lung injury. Am Rev Respir Dis. 1986;133(5):913-927.

34. Vauthier C, Bouchemal K. Methods for the preparation and manufacture of polymeric nanoparticles. Pharm Res. 2009;26(5):1025-1058.

35. Pohlmann AR, Mezzalira G, Venturini Cde G, et al. Determining the simultaneous presence of drug nanocrystals in drug-loaded polymeric nanocapsule aqueous suspensions: a relation between light scattering and drug content. Int J Pharmac. 2008;359:288-293.

36. Bernardi A, Braganhol E, Jäger E, et al. Indomethacin-loaded nanocapsules treatment reduces in vivo glioblastoma growth in a rat glioma model. Cancer Lett. 2009;281:53-63.

37. Frozza RL, Bernardi A, Paese K, et al. Characterization of trans-resveratrol-loaded lipid-core nanocapsules and tissue distribution studies in rats. J Biomed Nanotechnol. 2010;6(6):694-703.

38. Frozza RL, Bernardi A, Hoppe JB, et al. Neuroprotective effects of resveratrol against $A \beta$ administration in rats are improved by lipid-core nanocapsules. Mol Neurobiol. 2013;47(3):1066-1080.

39. Schromm AB, Brandenburg K, Loppnow H, et al. Biological activities of lipopolysaccharides are determined by the shape of their lipid A portion. Eur J Biochem. 2000;267(7):2008-2013.

40. Morris M, Li L. Molecular mechanisms and pathological consequences of endotoxin tolerance and priming. Arch Immunol Ther Exp (Warsz). 2012;60(1):13-18.

41. Nakajima T, Suarez CJ, Lin KW, et al. T cell pathways involving CTLA4 contribute to a model of acute lung injury. $J$ Immunol. 2010;184(10): $5835-5841$.

42. Mirzapoiazova T, Kolosova IA, Moreno L, Sammani S, Garcia JG, Verin AD. Suppression of endotoxin-induced inflammation by taxol. Eur Respir J. 2007;30(3):429-435.

43. Amrani Y, Panettieri RA. Airway smooth muscle: contraction and beyond. Int J Biochem Cell Biol. 2003;35(3):272-276.

44. Shan X, Hu A, Veler H, et al. Regulation of Toll-like receptor 4-induced proasthmatic changes in airway smooth muscle function by opposing actions of ERK1/2 and p38 MAPK signaling. Am J Physiol Lung Cell Mol Physiol. 2006;291(3):L324-L333.

45. Mansson Kvarnhammar A, Tengroth L, Adner M, Cardell LO. Innate immune receptors in human airway smooth muscle cells: activation by TLR1/2, TLR3, TLR4, TLR7 and NOD1 agonists. PLoS One. 2013; 8(7):e68701.

46. de Siqueira RJ, Freire WB, Vasconcelos-Silva AA, et al. In-vitro characterization of the pharmacological effects induced by (-)-alphabisabolol in rat smooth muscle preparations. Can J Physiol Pharmacol. 2012;90(1):23-35.

47. Roberts RE, Allen S, Chang AP, et al. Distinct mechanisms of relaxation to bioactive components from chamomile species in porcine isolated blood vessels. Toxicol Appl Pharmacol. 2013;272(3):797-805.

48. Ligeiro-Oliveira AP, Fialho de Araujo AM, Lazzarini R, et al. Effects of amphetamine on immune-mediated lung inflammatory response in rats. Neuroimmunomodulation. 2004;11(3):181-190.

49. Ligeiro de Oliveira AP, Lazzarini R, Cavriani G, Quinteiro-Filho WM, Tavares de Lima W, Palermo-Neto J. Effects of single or repeated amphetamine treatment and withdrawal on lung allergic inflammation in rats. Int Immunopharmacol. 2008;8(9):1164-1171.

50. Leikauf GD, McDowell SA, Wesselkamper SC, et al. Acute lung injury: functional genomics and genetic susceptibility. Chest. 2002; 121(3 Suppl):70S-75S.

51. Silliman CC, Voelkel NF, Allard JD, et al. Plasma and lipids from stored packed red blood cells cause acute lung injury in an animal model. J Clin Invest. 1998;101(7):1458-1467.

52. Grommes J, Soehnlein O. Contribution of neutrophils to acute lung injury. Mol Med. 2011;17(3-4):293-307. 
53. Yao HY, Zhang LH, Shen J, et al. Cyptoporus polysaccharide prevents lipopolysaccharide-induced acute lung injury associated with downregulating Toll-like receptor 2 expression. J Ethnopharmacol. 2011; 137(3):1267-1274.

54. McKay DL, Blumberg JB. A review of the bioactivity and potential health benefits of chamomile tea (Matricaria recutita L.). Phytother Res. 2006;20(7):519-530.

55. Rocha NF, Rios ER, Carvalho AM, et al. Anti-nociceptive and antiinflammatory activities of (-)-alpha-bisabolol in rodents. Naunyn Schmiedebergs Arch Pharmacol. 2011;384(6):525-533.

56. Call DR, Nemzek JA, Ebong SJ, et al. Differential local and systemic regulation of the murine chemokines KC and MIP2. Shock. 2001; 15(4):278-284.

57. Zwahlen R, Walz A, Rot A. In vitro and in vivo activity and pathophysiology of human interleukin-8 and related peptides. Int Rev Exp Pathol. 1993;34 Pt B:27-42.

58. Baggiolini M, Dewald B, Moser B. Interleukin-8 and related chemotactic cytokines - CXC and CC chemokines. Adv Immunol. 1994;55: 97-179.

59. Chi H, Barry SP, Roth RJ, et al. Dynamic regulation of pro- and anti-inflammatory cytokines by MAPK phosphatase 1 (MKP-1) in innate immune responses. Proc Natl Acad Sci US A. 2006;103(7):2274-2279.

60. De Filippo K, Henderson RB, Laschinger M, Hogg N. Neutrophil chemokines $\mathrm{KC}$ and macrophage-inflammatory protein-2 are newly synthesized by tissue macrophages using distinct TLR signaling pathways. J Immunol. 2008;180(6):4308-4315.
61. Liu S, Feng G, Wang GL, Liu GJ. p38MAPK inhibition attenuates LPS-induced acute lung injury involvement of NF-kappaB pathway. Eur J Pharmacol. 2008;584(1):159-165.

62. Xu GL, Yao L, Rao SY, Gong ZN, Zhang SQ, Yu SQ. Attenuation of acute lung injury in mice by oxymatrine is associated with inhibition of phosphorylated p38 mitogen-activated protein kinase. J Ethnopharmacol. 2005;98(1-2):177-183.

63. Gao M, Chen L, Yu H, Sun Q, Kou J, Yu B. Diosgenin down-regulates NF-kappaB p65/p50 and p38MAPK pathways and attenuates acute lung injury induced by lipopolysaccharide in mice. Int Immunopharmacol. 2013;15(2):240-245.

64. Schuh K, Pahl A. Inhibition of the MAP kinase ERK protects from lipopolysaccharide-induced lung injury. Biochem Pharmacol. 2009; 77(12):1827-1834.

65. Liang XM, Guo GF, Huang XH, Duan WL, Zeng ZL. Isotetrandrine protects against lipopolysaccharide-induced acute lung injury by suppression of mitogen-activated protein kinase and nuclear factor-kappa B. J Surg Res. 2014;187(2):596-604.

66. Kim S, Jung E, Kim JH, Park YH, Lee J, Park D. Inhibitory effects of (-)- $\alpha$-bisabolol on LPS-induced inflammatory response in RAW264.7 macrophages. Food Chem Toxicol. 2011;49(10):2580-2585.
International Journal of Nanomedicine

\section{Publish your work in this journal}

The International Journal of Nanomedicine is an international, peerreviewed journal focusing on the application of nanotechnology in diagnostics, therapeutics, and drug delivery systems throughout the biomedical field. This journal is indexed on PubMed Central, MedLine, CAS, SciSearch $®$, Current Contents $\AA /$ Clinical Medicine,

\section{Dovepress}

Journal Citation Reports/Science Edition, EMBase, Scopus and the Elsevier Bibliographic databases. The manuscript management system is completely online and includes a very quick and fair peer-review system, which is all easy to use. Visit http://www.dovepress.com/ testimonials.php to read real quotes from published authors. 